\title{
Women's Awareness and Attitude Toward Breast Self-Examination in Dezful City, Iran, 2013
}

\author{
Hadi Zare Marzouni ${ }^{1}$; Zohreh Lavasani ${ }^{2}$; Minoo Shalilian ${ }^{1}$; Reza Najibpour ${ }^{3}$; Masoud \\ Saadat Fakhr ${ }^{1}$; Reza Nazarzadeh ${ }^{1}$; Ali Farshad ${ }^{3}$; Nosrat Bahrami ${ }^{4,}$ \\ ${ }^{1}$ Student Research Committee, Dezful University of Medical Sciences, Dezful, IR Iran \\ ${ }_{2}^{2}$ Student Research Committee, Mashhad University of Medical Sciences, Mashhad, IR Iran \\ ${ }^{3}$ Student Research Committee, Tehran Medical Sciences Branch, Islamic Azad University, Tehran, IR Iran \\ ${ }^{4}$ Department of Midwifery, Faculty of Nursing and Midwifery, Dezful University of Medical Sciences, Dezful, IR Iran \\ ${ }^{*}$ Corresponding Author: Nosrat Bahrami, Department of Midwifery, Faculty of Nursing and Midwifery, Dezful University of Medical Sciences, Dezful, IR Iran. Tel: +98-6416269532, Fax: \\ +98-6416269041, E-mail: bahrami.n@dums.ac.ir
}

Received: January 28, 2014; Revised: June 30, 2014; Accepted: August 10, 2014

\begin{abstract}
Background: Over one million new cases of breast cancer $(\mathrm{BC})$ are diagnosed each year with a mortality rate of more than 600 thousand women per year. Breast self-examination (BSE) is a patient-centered, inexpensive, and noninvasive diagnostic test. We focused on the role of screening in $\mathrm{BC}$ in early diagnosis.

Objectives: The purpose of this study was to evaluate awareness and attitude of women toward BSE in Dezful City, Iran, in 2013.

Patients and Methods: This descriptive cross-sectional study included 1020 women over 15 years of age in Dezful City, in 2013. Simple random clustering was used to enroll accessible women. We have applied the available pieces of software for statistical analysis.

Results: The mean age of recruited women was $37.1 \pm 1.3$ and $23.6 \%$ of participants had a history of $\mathrm{BC}$ in themselves or in their relatives (mother, sister, aunt, and grandmother). In addition, 70.1\% of participants benefited from early diagnosis of BC, 83.3\% of participants considered BSE necessary and useful for early diagnosis of BC, and 51\% of them performed BSE. There was a statistically significant correlation between being married and doing BSE $(\mathrm{P}=0.034)$ and between women's level of education and awareness to perform BSE $(\mathrm{P}$ $=0.009$ ).

Conclusions: With regard to high prevalence of BC in Iran, this study showed a positive attitude of women in Dezful City toward BSE. Health policymakers in Dezful City can establish training programs to increase women's awareness of BSE and to instruct them to perform it properly.
\end{abstract}

Keywords:Breast Cancer; Self-Examination; Awareness; Attitude

\section{Background}

Cancer is the main health problem of many countries throughout the world. Epidemiologic researches in the United States reveal that one out of four deaths is due to cancer $(1,2)$. Breast cancer (BC) is the most common type of cancer among women worldwide, which accounts for approximately one-fifth of all deaths in women aged 40 to 50 years $(2,3)$. The most common and fatal cancer in women is $\mathrm{BC}$ while the most common cancer in men is lung cancer (1). Over one million new cases of $\mathrm{BC}$ are diagnosed each year and more than 600000 of them would lead to death. BC comprises $22 \%$ of all cancers (4). It is a worldwide-growing public health problem, specially in developing countries so that its incidence has increased to $5 \%$ peryear (5). The proportion of death because of BC in developing countries is higher than developed countries. Although just half of the cases of $\mathrm{BC}$ occur in developing countries, two-thirds of deaths due to $\mathrm{BC}$ occur in these countries (6). Regardless of their age, all of the women are at risk for BC; however, aging increases its risk. BC prevalence in the world is increasing and it has had a concerning incremental trend in Iran (7), where its incidence was estimated at 20 per 105 women, and one of every ten women would develop BC during her life $(8,9)$. Since all cases of BC are not registered in Iran, we cannot comment on its prevalence, incidence, and fatality. nonetheless, BC rate in Iran is estimated at 20 new cases in 100000 female (10). Moreover, although BC is not preventable, we can increase patient's survival by more than $90 \%$ through early diagnosis (11). There are different ways for early diagnosis of BC including breast self-examination (BSE), physical exam by a physician, and mammography; however, unfortunately, it is not diagnosed in early stages of the disease in many patients when they are mostly curable. In developed countries, most of women use screening tests and it has caused a reduction in BC mortality rates. nevertheless, the condition is not the same in developing countries (12). In many countries, mammography is the best screening test for diagnosis of BC at early stages (13). 
Zare Marzouni H et al.

In Iran, with regard to growing rate of $\mathrm{BC}$ and referring of patients in advanced stages of the disease, it is necessary to improve patient's attitude towards BC by performing behavior remodeling programs (14) among which BSE is available and inexpensive and women show tendency to perform it (15). By means of monthly correct BSE, women become familiar with their breast's characteristics and can distinguish abnormal changes in future and in case of any unnatural changes, it would be diagnosed at early stages. If all of the women examine their breasts monthly and refer to the physician for further physical exam and mammography on time, It would be possible to prevent BC's progression to high stages of the disease in $95 \%$ of cases (16). The sooner the cancer is diagnosed, the lower the needed radiotherapy would be and hence, the higher the patient's quality of life would be. The reasons that prevent women from performing regular BSE include disorientation about exam importance, fear and anxiety, and unawareness of correct way of performing exam (17-19). Studies showed that women with higher information about BSE would perform it correctly and regularly (16). Researches imply that awareness of and attitude of people toward applying diagnostic tests vary. A study on awareness and attitude of female employees of Education Ministry toward BC in Shahrekord City in 2008 showed that the attitude was very good in $15.53 \%$, good in $17 \%$, and poor in $10.95 \%(20)$. In a similar study in Kashan City in 2001, $42 \%$ had poor attitude and $5.5 \%$ had negative and apathetic attitude toward BSE (21). BC is the most common cancer and the most common cause of death from cancer in women (1). BC mortality rate is increasing in women. A study about women's awareness of mammography, BSE, and other diagnostic methods in at-risk women has not been done in Dezful city yet.

\section{Objectives}

Our study aimed to evaluate the awareness of and attitude toward BSE, which is one of the most simple diagnostic methods, among women in Dezful City, Iran, in 2013 Health policymakers would use the results to design training programs on BSE and provide information on correct performance of the examination.

\section{Patients and Methods}

This descriptive cross-sectional study included 1020 women over 15 years of age and was performed in 2013 . Simple random cluster of accessible women was used to recruit participants. Sampling communities included women referred to Medical Centers (rural and urban), students of Dezful University of Medicine, students of Dezful Azad Islamic University, students of Jundishapour Engineering University, students of rural and urban high schools in Dezful City and homemakers in five Dezful City municipal districts. Sample size was calculated by the following formula:

$$
\mathrm{n}=\left[(\mathrm{z}+\mathrm{z}) \sigma /\left(\mu_{1}-\mu_{0}\right)\right]^{2}
$$

$=0.05$

$1-=0.80$

Educated females were evaluated through questionnaire and illiterates through face-to-face interview. Questionnaire included five sections: first section was the form of giving consent; second section included sample's demographic characteristics; third section included sample's awareness of BC, which according to standard protocols, consisted of prevalence, risk factors, sign and symptoms, BSE, clinical breast exam, and mammography (22); fourth section included women awareness of and attitude toward BSE questionnaire; fifth section included assessment of BC risk factors in samples. The questionnaire was delivered to women by female executives. The responses to 20 questions of questionnaires were calculated as follows: correct, 1; false, -1; and "I don't know", 0. Then the sum of them was classified to four levels, which was adjusted by Likert scale (good, 11-20; moderate, 1-10; and bad, 0 to -10 ). Validity questionnaire was validated using content validity method by five internal medicine specialists, endocrinologist, and immunologist in Dezful University of Medical Sciences. Reliability of this questionnaire was obtained by test-retest in which by a pilot study on 60 persons Cronbach's alpha of 0.86 was obtained. Questionnaire with incomplete forms were excluded. Data was analyzed by SPSS 13 (SPSS Inc., Chicago, IL, USA) using mean, absolute, and relative frequencies. In order to assess parameter's association, we used independent-samples t test and Chi square test. $\mathrm{P}<0.05$ was considered as statistically significant. The Ethics Committee of Dezful University of Medical Sciences approved the study protocol (Code of ethical approval, DURs104). In this study, sampling strategy and inability to generalized finding to target population was one of the basic limitation. Study about women's awareness of mammography, BSE, and other diagnostic ways has not been done in Dezful yet.

\section{Results}

In this study, we had 1020 participants with mean age of $37.1 \pm 1.3$ years (range, 15-79). In this study, 195 women $(19.1 \%)$ were single and the rest were married. The education level was under high school diploma in 385 women (37.7\%), high school diploma in 295 (28.9\%), and academic education in 340 (33.3\%). Among the participants, 630 women (61.8\%) were housekeeper, 170 (16.7\%) were employed, and 220 (21.6\%) were students. Mean of body mass index of participants was 26.7. Table 1 shows demographic characteristics of participants. The history of BC in family members (mother, aunt, and grandmother) was reported by $7.8 \%$ of women and $10.8 \%$ of women had history of BC in distant relatives (Table 2). Table 3 shows frequency and percentage of women's responses to questionnaire. Most of participants (72\%) believed that breast physical exam and mammography are efficient medical diagnostic ways. Although 685 women 
(67.2\%) knew that monthly BSE was necessary, only 426 (41.8\%) knew its proper time. The participant's awareness of risk factors and symptoms of BC was not satisfactory. The results of this study showed that the mean score of women's knowledge $51.24 \pm 7.12$ (median, 53.17; interquartile range [IQR], 17.43). Participant's knowledge about BC and its screening tests was good in 206 women (20.2\%), moderate in $783(76.8 \%)$, and poor in 31 (3\%). The positive therapeutic effects of early diagnosis were acknowledged by 715 women (70.1\%). Although 525 women (51.5\%) performed BSE, only 400 (39.2\%) knew how to do it correctly. The results of this study showed that the mean score of women's attitude was 74.12 \pm 11.83 (median, 67.71; IQR, 25.03). Overall, 83.3\% of participants believed that BSE would have positive effects in early diagnosis of BC, $82.4 \%$ believed that BSE was not unpleasant, $47.1 \%$ believed that BSE was an appropriate way of BC diagnosis, and $72.5 \%$ believed that it is necessary to train all of the women on performing BSE correctly. Only $37 \%$ of participants were trained on examining their breasts themselves and among training sources, healthcare staff were the most important sources (38.2\%). Among the reasons of not doing BSE, the most important ones were consecutively "not knowing how to do it" and "not having breast problems”. The participants' attitude toward BSE is shown in Table 4. Although 51.5\% of women performed BSE, only $33.3 \%$ of women over 40 years of age performed it and $31.8 \%$ of them knew how to do it correctly $(\mathrm{P}<0.001)$. Table 5 shows participant's BSE proportions in different age ranges and shows whether they were trained how to do it. Chi-square test showed statistically significant association between participant's awareness of and attitude toward BSE. It showed that the higher the level of awareness was, the more positive the attitude would be $(\mathrm{P}<0.001)$. The results showed the same association between participant's attitude and function. It means that those who had a more positive attitude did the exam more frequently $(\mathrm{P}<0.001)$. There was statistically significant association between participant's awareness with age (odds ratio $[\mathrm{OR}]=1.58$; $\mathrm{P}<0.001)$, marital status $(\mathrm{OR}=1.3 ; \mathrm{P}=0.021)$, education $(\mathrm{OR}=2.2 ; \mathrm{P}=0.001)$, a positive family history $(\mathrm{OR}=3.45$, $\mathrm{p}<0.001)$. There was a statistically significant correlation between participant's attitude with age $(\mathrm{OR}=2.70$; $\mathrm{P}<0.001)$, marital status $(\mathrm{OR}=1.6 ; \mathrm{P}=0.040)$, education level ( $\mathrm{OR}=1.9 ; \mathrm{P}=0.001)$, previous training history ( $\mathrm{OR}$ $=3.4 ; \mathrm{P}<0.001)$, and positive family history $(\mathrm{OR}=2.4 ; \mathrm{P}$ $<0.001)$. There was an statistically significant relation between doing BSE with age $(\mathrm{OR}=2.4, \mathrm{P}<0.001)$, marital status $(\mathrm{OR}=2.01, \mathrm{P}<0.001)$, education $(\mathrm{OR}=1.5, \mathrm{P}=$ $0.015)$, previous training $(\mathrm{OR}=1.08, \mathrm{P}<0.001)$, positive family history $(\mathrm{OR}=2.6, \mathrm{P}<0.001)$ and participant's attitude to do the test $(\mathrm{OR}=1.12, \mathrm{P}=0.004)$, but it does not have significant relation with test unpleasantness $(\mathrm{P}=$ 0.682). There was a statistically significant correlation between education level and knowing to do the test $(\mathrm{P}=$ 0.009). In addition, those who were trained on perform- ing the test, did it more frequently $(\mathrm{P}<0.001)$. Doing the test properly had a direct correlation with level of education $(\mathrm{P}<0.001)$.

Table 1. Frequency Distribution and Individual Characteristics of Participants' Referred to Dezful City Medical Centers in 2013

\begin{tabular}{lc}
\hline Individual Characteristics & No. $(\%)$ \\
\hline Age, $\mathbf{y}$ & \\
\hline $15-20$ & $270(26.5)$ \\
\hline $20-30$ & $215(21.1)$ \\
$30-40$ & $205(20.1)$ \\
\hline $40-50$ & $155(15.2)$ \\
\hline$>50$ & $175(17.2)$ \\
\hline Marital Status & \\
\hline Single & $195(19.1)$ \\
\hline Married & $825(80.9)$ \\
\hline Occupation & \\
\hline Housekeeper & $630(61.8)$ \\
\hline Employed & $170(16.7)$ \\
\hline Student & $220(21.6)$ \\
\hline Education & \\
\hline Under high school diploma & $385(37.7)$ \\
\hline High school diploma & $295(28.9)$ \\
\hline Bachelor & $305(29.9)$ \\
\hline Master and PHD & $35(3.4)$ \\
\hline Body mass index & $25(2.5)$ \\
\hline Underweight (<19) & $345(33.8)$ \\
\hline Normal (19-25) & $1820(10.1)$ \\
\hline Overweight (25-30) & \\
\hline Obese class1 (moderately obese; $30-35)$ & \\
\hline Obese class2 (severely obese; $0>35)$ & \\
\hline
\end{tabular}

Table 2. Frequency Distribution of Positive Family History of Breast Cancer in Women Between Fifteen and Sixty-Nine Years in Dezful City, 2013

\begin{tabular}{lc}
\hline Family History of Breast Cancer & No. (\%) \\
\hline Participant & $12(1.2)$ \\
Mother and Sister & $19(1.9)$ \\
Aunt & $48(4.7)$ \\
Distant Relatives & $110(10.8)$ \\
Negative Family History & $831(81.5)$ \\
Total & $1020(100)$ \\
\hline
\end{tabular}


Zare Marzouni Het al.

\begin{tabular}{|c|c|c|c|}
\hline Parameters & Yes & No & I Don't Know \\
\hline Prevalence & $221(21.7)$ & $363(35.6)$ & $436(42.7)$ \\
\hline \multicolumn{4}{|l|}{ Risk factors } \\
\hline Incidence age is in women over 50 years. & $91(8.9)$ & $853(83.6)^{b}$ & $76(7.5)$ \\
\hline Having low-fat high-fiber diet increases breast cancer risk. & $741(72.7)^{b}$ & $87(8.5)$ & $192(18.8)$ \\
\hline Being in contact with a person with breast cancer increases cancer risk. & $72(7.1)$ & $813(79.7)^{b}$ & $135(13.2)$ \\
\hline Presence of breast cancer in mother, sister, or aunt increases cancer risk. & $\begin{array}{l}679(66.6) \\
b\end{array}$ & $146(14.3)$ & $195(19.1)$ \\
\hline \multicolumn{4}{|l|}{ Breast cancer is curable if diagnosed early. } \\
\hline Sign and symptoms & $715(70.1)^{b}$ & $126(12.4)$ & $179(17.5)$ \\
\hline Green liquid excretion from nipple & $306(30)$ & $135(13.2)^{b}$ & $579(56.8)$ \\
\hline Presence of mass without pain & $469(46)^{b}$ & $438(42.9)$ & $113(11.1)$ \\
\hline Arm swelling & $268(26.3)^{b}$ & $211(20.7)$ & $541(53)$ \\
\hline Milky excretion from nipple in a virgin & $302(29.6)$ & $334(32.7)^{\mathrm{b}}$ & $384(37.6)$ \\
\hline Periareolar granular bulging & $204(20)$ & $267(26.2)$ & $549(53.8)$ \\
\hline Nipple retraction & $443(43.4)^{b}$ & $216(21.2)$ & $361(35.4)$ \\
\hline Painless mass in axilla & $461(45.2)^{\mathrm{b}}$ & $237(23.2)$ & $322(31.6)$ \\
\hline \multicolumn{4}{|l|}{ Breast self-examination and clinical breast exam } \\
\hline Breast Self-Examination should be performed monthly after 20 years. & $685(67.2)^{b}$ & $147(14.4)$ & $188(18.4)$ \\
\hline Yearly breast exam by physician can lead to early diagnosis. & $874(85.7)^{b}$ & $45(4.4)$ & $101(9.9)$ \\
\hline The best time for breast self-examination is on the first day or in mid menstrual period. & $521(51.1)$ & $426(41.8)^{b}$ & $73(7.1)$ \\
\hline \multicolumn{4}{|l|}{ Mammography } \\
\hline $\mathrm{X}$-Ray is used in mammography. & $622(61)^{b}$ & $75(7.3)$ & $323(31.7)$ \\
\hline Mammography helps breast cancer early diagnosis. & $734(72)^{b}$ & $37(3.6)$ & $249(24.4)$ \\
\hline $\begin{array}{l}\text { Mammography should be done yearly after } 50 \text { and between } 40 \text { to } 50 \text { in condition of } \\
\text { physician's prescription. }\end{array}$ & $464(45.5)$ & $211(20.7)$ & $345(33.8)$ \\
\hline $\begin{array}{l}\text { If there is not a mass in breast and the patient is asymptomatic, according to patient age, } \\
\text { mammography is prescribed to rule out cancer. }\end{array}$ & $588(57.7)^{\mathrm{b}}$ & $135(13.2)$ & $297(29.1)$ \\
\hline
\end{tabular}

\begin{tabular}{lc}
\hline Table 4. Women Attitude Toward Breast Self-Examination and Learning Sources & No. $(\%)$ \\
\hline Attitude & $65(6.4)$ \\
\hline Breast self-examination & $90(8.8)$ \\
\hline Unpleasant & $480(47.1)$ \\
\hline There is no need to do it. & $175(17.2)$ \\
\hline It is better to do it. & $210(20.6)$ \\
\hline It is very useful for diagnosis. & $1020(100)$ \\
\hline It is essential for early diagnosis. & $150(14.7)$ \\
\hline Total & $90(8.8)$ \\
Women Who need to be trained & $40(3.9)$ \\
\hline Married women & $740(72.5)$ \\
\hline Women over 35 years & $1020(100)$ \\
\hline Women with positive family history of breast cancer & \\
\hline All women in all range of age & $250(24.5)$ \\
\hline Total & $115(11.3)$ \\
The best source of training & $390(38.2)$ \\
\hline Physicians & $90(8.8)$ \\
\hline Relatives & $175(17.2)$ \\
\hline Healthcare staff & $1020(100)$ \\
\hline Training brochures & \\
\hline Media & \\
\hline Total &
\end{tabular}


Zare Marzouni Het al.

\begin{tabular}{|c|c|c|c|c|c|c|c|}
\hline \multirow[t]{2}{*}{ Parameters } & \multicolumn{5}{|c|}{ Age, $y$} & \multirow[t]{2}{*}{ Total } & \multirow[t]{2}{*}{ P Value } \\
\hline & 15-20 & 20-30 & $30-40$ & 40-50 & $>50$ & & \\
\hline Breast self-examination performance & & & & & & & $>0.001$ \\
\hline Yes & $100(37)$ & $165(76.7)$ & $150(73.2)$ & $60(28.7)$ & $50(28.6)$ & $525(51.5)$ & \\
\hline No & $170(63)$ & $50(24.3)$ & $55(26.8)$ & $95(61.3)$ & $125(71.4)$ & $495(49.5)$ & \\
\hline Total & $270(100)$ & $215(100)$ & $205(100)$ & $155(100)$ & $175(100)$ & $1020(100)$ & \\
\hline Being trained & & & & & & & $>0.001$ \\
\hline Yes & $110(40.7)$ & $130(60.5)$ & $155(75.6)$ & $45(20)$ & $60(34.3)$ & $500(49)$ & \\
\hline No & $160(59.3)$ & $85(39.5)$ & $50(24.4)$ & $110(80)$ & $115(65.7)$ & $520(51)$ & \\
\hline Total & $270(100)$ & $215(100)$ & $205(100)$ & $155(100)$ & $175(100)$ & $1020(100)$ & \\
\hline
\end{tabular}

\section{Discussion}

Our study evaluated the degree of awareness and attitude of women about BC and BSE in Dezful City for the first time. We tried to study the association of women's attitude toward BSE with parameters such as age, marital status, education, occupation, and family history (BC grade 1,2 ). The results of this study approved results of other studies on the positive effects of elevating women's awareness of and attitude toward BC on their participation in screening programs. The responses to the questionnaire about BC and its preventive routes in women in Dezful City showed that only $20.2 \%$ of participants had a good level of knowledge and the rest had moderate to poor knowledge of this issue. A survey by Jokar and Ghiasi in 1997 about women's awareness of and attitude toward BC in Ilam Province showed that most of them (57.3\%) had poor awareness and only $11.9 \%$ had good awareness (22). Moreover an study by Abedzadeh et al. on women's attitude toward BC and its screening tests showed that $42 \%$ of Kashan City's women did not know about BC screening tests and only $22 \%$ were informed (23). In a study by Jokar and Ghiasi the women's awareness of and attitude toward BC was good in $28.5 \%$, moderate in $67.3 \%$, and poor in $4.2 \%$. The women's awareness of positive effects of early diagnosis of BC was $89 \%$ but this proportion was reduced to $70.1 \%$ in Dezful City's women in our study. The results of mentioned studies show women's information has increased at present time. Nevertheless, our research shows that Dezful City women's information has not increased with the same anticipated rate. According to our results, $51.5 \%$ of Dezful City's women performed BSE, $82.4 \%$ of them had a positive attitude toward the test, and $83.3 \%$ believed that the test has a positive effect in early diagnosis of BC. In a study by Jokar and Ghiasi in $1998,64 \%$ of women had positive attitude toward breast screening tests and $35 \%$ of them did the BSE (22). A study by Abedzadeh et al. showed that $94.5 \%$ of women had a positive attitude toward BSE, $42.7 \%$ of them perform it, and $19.7 \%$ were referred to healthcare staff to do it for them (23). A study by Banaiyan et al. on women's awareness of and attitude toward BC screening tests in Brijen City in 2004, showed that only
$16.7 \%$ of women had a positive attitude towards screening tests, $67.7 \%$ had moderate attitude, and $15.6 \%$ had negative attitude. Women's attitude toward BSE was only positive in $23 \%$ and only $47.1 \%$ performed the exam (24). A study by Vietri et al. in the United States in 1997 showed that 58\% of women performed BSE (25), which was higher than the rate by Dezful women. This result showed that women's culture has an important role in this difference and more efforts are needed to inform women and make BSE important for them in developing countries. This issue showed us that to design training programs, we should consider two important points: 1) providing appropriate BSE training programs to diagnose it earlier; and 2) explaining its benefits to women. Parameters such as age, education, marital status, and family history would affect the knowledge level of participants. Women over 20 years of age with higher education and positive family history of $\mathrm{BC}$ had better information about $\mathrm{BC}$ preventing programs $(\mathrm{P}>0.001)$. These results were in parallel with many researches performed until now $(23,24)$. With regard to the higher level of education in Iranian women than women in Central Asia, Middle East, Caucasus, Africa, and South America, it seems that designation and performing training interventional health programs on cancers, especially BC, would improve establishment of BC screening tests in Iranian women in comparison with above countries. In other words, interventional health training programs increase women's awareness of and attitude toward cancers, specially BC, and their screening and early diagnostic tests. In women with higher education level, there is a higher awareness of this issue. Bastani et al. studied healthcare staff with high level of education and appropriate knowledge about BC and its screening tests. The results showed that their tendency toward participating in $\mathrm{BC}$ screening tests was higher than was in general population (26). According to this survey, most of these women prefer BSE in comparison with other screening tests. A survey by Levshin et al. on 1500 cases of BC showed that $81 \%$ of them had noticed its symptoms themselves first (27). In conclusion, if women 
learn BC's sign and symptoms and perform BSE monthly, it would be possible to diagnose BC in early stages, which would provide a better diagnosis. With regard to high prevalence of $\mathrm{BC}$ in Iran and considering the positive awareness of Dezful City's women about BSE, which was shown in our study, and paying attention to the fact that our target population lacked information about $\mathrm{BC}$, we need interventional health training programs and regular screening tests in Iran. We suggest the following ways in order to reduce mortality rate of $\mathrm{BC}$ :

1) Regular interventional health training programs performance to elevate awareness and attitude of women over 15 years toward cancers, especially BC.

2) Establishment of nongovernmental organizations (NGO) and support them to inform the people.

3) Establishing cancer clinics in each city.

4) Active screening tests and clinical breast exam and mammography by physicians in rural and urban health centers for women over 40 years.

Health policymakers of Dezful City can establish BSE training programs to elevate women's awareness of and attitude toward early diagnosis of BC and BSE.

\section{Acknowledgements}

We are indebted to all women and their families who took part in the project. We appreciate the Research Deputy of Dezful University of Medical Sciences for providing the financial support.

\section{Authors' Contributions}

Study concept and design: Hadi Zare Marzouni, Masoud Saadat Fakhr; acquisition of data, analysis and interpretation of data: Minoo Shalilian, Hadi Zare Marzouni; drafting of the manuscript: Zohreh Lavasani and Reza Nazarzadeh; critical revision of the manuscript for important intellectual content: Nosrat Bahrami; statistical analysis, administrative, technical, and material support: Hadi Zare Marzouni, Reza Najibpour, and Ali Farshad; study supervision: Nosrat Bahrami.

\section{Funding/Support}

The Research Deputy of Dezful University of Medical Sciences provided financial support.

\section{References}

1. Siegel R, Ward E, Brawley O, Jemal A. Cancer statistics, 2011: the im pact of eliminating socioeconomic and racial disparities on premature cancer deaths. CA Cancer JClin. 2011;61(4):212-36.

2. Shabani M, Moghimi M, Eghdam Zamiri R, Nazari F, Mousavinasab N, Shajari Z. Life skills training effectiveness on non-metastatic breast cancer mental health: a clinical trial. Iran Red Crescent Med J. 2014;16(1).

3. Key TJ, Verkasalo PK, Banks E. Epidemiology of breast cancer. Lancet Oncol. 2001;2(3):133-40.

4. Voogd AC, van Oost FJ, Rutgers EJ, Elkhuizen PH, van Geel AN, Scheijmans LJ, et al. Long-term prognosis of patients with local recurrence after conservative surgery and radiotherapy for early breast cancer. Eur J Cancer. 2005;41(17):2637-44.
5. Groot MT, Baltussen R, Uyl-de Groot CA, Anderson BO, Hortobagyi GN. Costs and health effects of breast cancer interventions in epidemiologically different regions of Africa, North America, and Asia. Breast J. 2006;12 Suppl 1:S81-90.

6. Yen JY, Ko $\mathrm{CH}$, Yen CF, Yang MJ, Wu CY, Juan $\mathrm{CH}$, et al. Quality of life, depression, and stress in breast cancer women outpatients receiving active therapy in Taiwan. Psychiatry Clin Neurosci. 2006;60(2):147-53.

7. Mehrabi Y, Yavari P, Abadi A. A study of cancer patterns among inpatients of public hospitals in Iran. Asian Pac J Cancer Prev. 2004;5(4):387-92.

8. Miller AB, Wall C, Baines CJ, Sun P, To T, Narod SA. Twenty five year follow-up for breast cancer incidence and mortality of the Canadian National Breast Screening Study: randomised screening trial. BMJ. 2014;348:g366.

9. Jarvandi S, Montazeri A, Harirchi I, Kazemnejad A. Beliefs and behaviours of Iranian teachers toward early detection of breast cancer and breast self-examination. Public Health. 2002;116(4):245-9.

10. Davidson T. Abortion and breast cancer: a hard decision made harder. Lancet Oncol. 2001;2(12):756-8.

11. Parkin DM, Bray FI, Devesa SS. Cancer burden in the year 2000. The global picture. EurJ Cancer. 2001;37 Suppl 8:S4-66.

12. Elmore JG, Armstrong K, Lehman CD, Fletcher SW. Screening for breast cancer. JAMA. 2005;293(10):1245-56.

13. Azaiza F, Cohen M. Health beliefs and rates of breast cancer screening among Arab women. J Womens Health (Larchmt). 2006;15(5):520-30.

14. Roth MY, Elmore JG, Yi-Frazier JP, Reisch LM, Oster NV, Miglioretti DL. Self-detection remains a key method of breast cancer detection for U.S. women. J Womens Health (Larchmt). 2011;20(8):1135-9.

15. Coe K, Harmon MP, Castro FG, Campbell N, Mayer JA, Elder JP. Breast self-examination: knowledge and practices of Hispanic women in two southwestern metropolitan areas. J Community Health. 1994;19(6):433-48.

16. Petro-Nustas W. Health-related behaviors and lifestyle factors of patients with breast cancer. Cancer Nurs. 2002;25(3):219-29.

17. Pfeiffer RM, Park Y, Kreimer AR, Lacey JJ, Pee D, Greenlee RT, et al Risk prediction for breast, endometrial, and ovarian cancer in white women aged 50 y or older: derivation and validation from population-based cohort studies. PLoS Med. 2013;10(7).

18. Sadler GR, Dhanjal SK, Shah NB, Shah RB, Ko C, Anghel M, et al. Asian Indian women: knowledge, attitudes and behaviors toward breast cancer early detection. Public Health Nurs. 2001;18(5):357-63.

19. Danesh A, Amiri M, Zamani AR, Azhibi M, Gorji F. Evaluation of awareness and attitude of female employees of Shahrekord education ministry branch about breast self exam. J Shahrekord Univ Med Sci. 2001;4(2):47-52.

20. Abedzadeh M, Sadat Z, Saberi F. Evaluation of awareness and attitude of women refered to Kashan medical centers about breast cancer and its screening tests in 2010. J Kashan Univ Med Sci. 2002;26(7):85-92.

21. Baxter N, Canadian Task Force on Preventive Health C. Preventive health care, 2001 update: should women be routinely taught breast self-examination to screen for breast cancer? CMAJ. 2001;164(13):1837-46.

22. Jokar F, Ghiasi N. Awareness and attitude of Ilam women about breast cancer. Ilam Univ Med Sci. 1999;9(26):17-20.

23. Abedzadeh M, Sadat Z, Saberi F. Evaluation of awareness and at titude of women refered to Kashan medical centers about breas cancer and its screening tests in 2000. J Kashan Univ Med Sci. 2002;26(7):85-92.

24. Banaiyan S, Kazemian A, Kheiri S. Evaluation of awareness and attitude of women refered to Borujen medical centers about breast cancer screening tests in2004. J Shahrekord Univ Med Sci. 2004;7(4):28-34.

25. Vietri V, Poskitt S, Slaninka SC. Enhancing breast cancer screening in the university setting. Cancer Nurs. 1997;20(5):323-9.

26. Bastani R, Maxwell AE, Carbonari J, Rozelle R, Baxter J, Vernon S. Breast cancer knowledge, attitudes, and behaviors: a comparison of rural health and non-health workers. Cancer Epidemiol Biomark ers Prev. 1994;3(1):77-84.

27. Levshin V, Fedichkina T, Droggachih V. The experience of breast cancer screening [abstract]. EurJ Cancer. 1998;34:S95. 